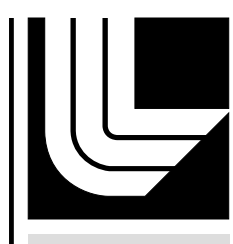

LAWRENCE LIVERMORE NATIONAL LABORATORY

\title{
Final Report Forensics City Transport 2012
}

B. W. Sleaford, T. E. Booth

October 11, 2012 
This document was prepared as an account of work sponsored by an agency of the United States government. Neither the United States government nor Lawrence Livermore National Security, LLC, nor any of their employees makes any warranty, expressed or implied, or assumes any legal liability or responsibility for the accuracy, completeness, or usefulness of any information, apparatus, product, or process disclosed, or represents that its use would not infringe privately owned rights. Reference herein to any specific commercial product, process, or service by trade name, trademark, manufacturer, or otherwise does not necessarily constitute or imply its endorsement, recommendation, or favoring by the United States government or Lawrence Livermore National Security, LLC. The views and opinions of authors expressed herein do not necessarily state or reflect those of the United States government or Lawrence Livermore National Security, LLC, and shall not be used for advertising or product endorsement purposes.

This work performed under the auspices of the U.S. Department of Energy by Lawrence Livermore National Laboratory under Contract DE-AC52-07NA27344. 
Brad Sleaford (LLNL) and Thomas E. Booth (Tech Source)

0 . Executive Summary

This project was to demonstrate practical Monte Carlo transport calculational methods applied to city models in prompt forensics. Typically 1 source gamma ray in $\sim 10^{18}$ is physically detected in most real world scenarios for this class of problems. Major factors are detector solid angles at $\sim \mathrm{km}$ distances, building and air attenuation, as well as huge variations in source intensities. We used the world-wide standard for transport calculations, MCNP, developed at LANL. We used ARA supplied city models used in consequence management. One indication of the extreme difficulty of these problems is that the huge numbers were larger than the space allotted by the code developers and were output as

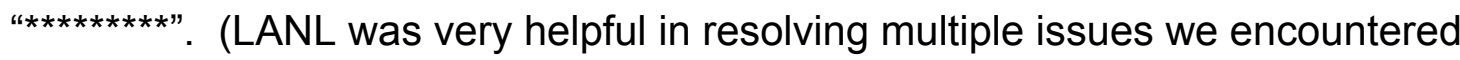
like this.) Hardware memory issues also needed to be resolved. Calculational success was achieved in the simpler WDC model by a combination of variance reduction, voxelized geometry eliminated the mcnp geometry errors in the NYC model, eliminating peripheral buildings, and convolution of the source terms.

1. Variance Reduction

Initial variance reduction efforts were somewhat stymied due to ARA's NYC input geometry errors and the fact that they were geometrically too large, requiring too much memory per node on the LC machines. This problem persisted for the $1^{\text {st }}$ year of this project. Subsequently the city models were changed to voxel models by ARA, which eliminated geometry errors.

Weight window and dxtran methods in monp were successfully applied, which provided NYC prompt nuclear forensics estimates for urban canyon geometry and single time slice sources. To help ensure reliable calculations, we inserted nonzero estimates in weight window regions where the weight window generator failed to produce estimates.

Further variance reduction investigations were deferred for NYC while WDC problem was evaluated using a convolution method and geometrical breakup of the problem. 
2. Convolution

The WDC problem greatly reduced the scatter due to low building heights. The city transport geometry was broken up to include only regions between the source and detectors. Additionally, the source was broken up for transport of each piece, then reconstructed via convolution. These steps provided the correct transported signal to the detectors.

3. Multi-source approach

MCNP was modified to simultaneously solve for multiple estimates due to multiple sources using a single transport calculation. With this modification, the convolution problem in section 2 is also solved within MCNP with very minimal post processing. A modified MCNP6 for this purpose has been delivered to LLNL for evaluation. Initial testing by Booth has been successful. Initial testing on LLNL problems is still to be done. One initial LLNL comment is that the convolution post processing mentioned in Section 2 should also be included in the multisource approach and all done entirely within MCNP.

4. Inverse Problem

A natural extension of the multisource approach is to express an unknown source as a function of parameters and solve for the parameter set that best matches a measured response. See the attached proposal, also documented in LLNL IM \#654892.

This work performed under the auspices of the U.S. Department of Energy by Lawrence Livermore National Laboratory under Contract DE-AC52-07NA27344. 